\title{
A Data Mining Approach For Product Promotion and Inventory Solution using FP-Growth Algorithm
}

\author{
Hartono \\ Faculty of Computer Science \\ Universitas Mercu Buana \\ Jakarta, Indonesia
}

\author{
Devi Fitrianah \\ Faculty of Computer Science \\ Universitas Mercu Buana \\ Jakarta, Indonesia
}

\begin{abstract}
This study aims to find interesting patterns on the database transaction so that it can be used as a recommendation sales promotion and inventory product. Companies have difficulty finding interesting transaction patterns in large databases, so it will be difficult to determine the right product promotions and inventory. To resolve these problems are to use data mining techniques with association rule. In previous studies, most studies adopt Apriori algorithm to analyze the association rules. In this study, the data mining technique used is the association rules algorithm FP-Growth. In the FP-Growth algorithm did generate candidates as in Apriori algorithm and using a development concept Tree in frequent itemset search so that it requires faster than Apriori. Some of the analyzes produced in this study are higher minimum support values and minimum trust used will result in fewer items and association rules. Association rule in this study has a lift ratio value of more than 1.00 , meaning that item $\mathrm{K}$ and $\mathrm{L}$ are actually bought together. The higher the lift ratio produced shows the stronger the association rules are formed. The results of this study are the minimum confidence of $97.63 \%$, the maximum trust is $99.37 \%$ and the lift ratio is 1,00013798 . These results can be used as recommendations for optimizing product promotions and inventory.
\end{abstract}

\section{General Terms}

Data Mining; Database; Fp-Growth; Association Rule; Algorithm

\section{Keywords}

Promotion, Knowledge Discovery Database Data Mining, Association Rule, Fp-Growth, frequent itemset.

\section{INTRODUCTION}

Trading business is one of the businesses selling various types of human goods in retail. Trading business competition is very tight so that appropriate market strategy are needed to support the increase in transaction value [1] and company profits. The good market strategy can be obtained by knowing the relationship between items purchased by customers, so it is necessary to do research and analysis of the database. This research was conducted with the aim to determine the pattern or relationship between the purchase of an item whether related and influence other items. Companies find it difficult to find interesting patterns of transactions in large database of sales transactions. So that it will have difficulty also in determining the right promotions and product inventory. The solutions to find interesting transaction patterns is to use Data Mining techniques. Data mining technique known as Knowledge Discovery in Database (KDD) is a method used in the analysis of large database observations to find interesting patterns of relationships of a transaction [2]. The pattern is then identified to determine the relationship between items and to determine the items most often purchased simultaneously using the Association rule method [2]. Previous research, most of the studies adopted the Apriori algorithm in analyzing association rule. In this study the data mining technique used is the association rule with the FPGrowth algorithm. The FP-Growth algorithm does not generate generate candidates as in the Apriori algorithm and uses the concept of Tree development in searching for Frequent Itemset [3] so it requires faster compared to Apriori. FP-Growth is a precise and fast algorithm for processing large amounts of data [4][5][6]. Some of the analyzes produced in this study are that the higher the minimum support and minimum confidence values used will result in fewer itemset and association rules. The association rules in this study has a lift ratio value of more than 1.00 , meaning that item $\mathrm{K}$ and $\mathrm{L}$ are actually bought together. The results of this study are the minimum confidence of $97.63 \%$, the maximum trust is $99.37 \%$ and the lift ratio is 1,00013798 . These results can be used as recommendations for optimizing product promotions and inventory so as to increase profits for the company.

The purpose of this study is:

1. Exploring hidden information from the database that can be a recommendation in making decisions to determine market strategies.

2. Presenting the association of items that are often purchased by customers so that they can be used to determine the right product promotion.

3. Presenting the fewest and most sold items in the dataset so that it can be used in managing inventory.

\section{LITERATURE REVIEW}

\subsection{Related Research}

The study was conducted referring to previous studies:

a. "Analisa Pola BelanjaMenggunakan algorithm FP Growth, Self Organizing Map (SOM) dan K Medoids" [7]. This research is about FP-Growth that is used to analyze items purchased simultaneously. Accurate results obtained from this study can be measured using a lift ratio. The Lift ratio shows a valid value in the transaction process that provides information on whether item $\mathrm{A}$ was purchased together with item B. A transaction is said to be valid if it has a lift ratio value of more than 1 , is that in the transaction, item A and B purchased simultaneously.

b. "ImplementasiAlgoritma FP-Growth Menggunakan Association Rule Pada Market Basket Analysis" [4]. With the results of the FP-Growth algorithm is more efficient in processing basket market or consumer shopping basket data, using the association rule can find 
out shopping rules consumers such as the relationships of each product purchased by consumers and affect the types of consumers with the products purchased and association rule can provide management decisions for product displays, promotions, marketing strategies.

\subsection{Association Rule}

Association rule mining is useful for discovering interesting relationships hidden in large data sets [8]. Association rules is data mining processes to find and determine all relationships between items in a database that meet minimum supports and minimum confidence [2]. Association rule is one method that aims to find patterns that often occur among many transactions, where each transaction consists of several items. In determining a relationship, there is interesting measure, that is:

(1) Support: support is a parameter that indicates the level of dominance of an item (item or itemset) over the whole transaction [9][10]. This measure is then used to determine whether an item or itemset meets the requirements in confidence.

(2) Confidence: confidence is a measure that shows the relationship between two items or items conditionally. Example, if confidence $\mathrm{K}$ and $\mathrm{L}$ are worth 1 (100\%), then it can be concluded that if the customer buys $\mathrm{K}$ definitely buy L. However, if the value of confidence is only close to 1 (eg 0.8), the conclusion is that if the customer buys the $\mathrm{K}$ item, it tends to buy L [7].

The support value for item $\mathrm{K}$ can be found by the following equation:

$$
\operatorname{Support}(K) \quad=\frac{\text { Number of transactions containing } K}{\text { Total transaction }}[1]
$$

And to get the minimum value of support for two items can be found with the following equation:

Support $(K, L)=\frac{\text { Number of transactions containing } K \text { and } L}{\text { Total transaction }}[2]$

After all patterns high frequency is found, then the rules are sought associative that meets the minimum requirements for confidenceby calculating the confidence of associative rules $\mathrm{K}$ $\rightarrow \mathrm{L}$. Scoreconfidence from the rules $\mathrm{K} \rightarrow \mathrm{L}$ is obtained from the equation:
Confidence $(K \rightarrow L)=\frac{\text { Number of transactions containing } K \text { and } L}{\text { Number of transactions containing } K}$ [11]

\subsection{FP-Growth}

This study uses a large database so that the FP-Growth algorithm is very appropriate to be used in this study. FPGrowth algorithm is an alternative algorithm that is quite effective against finding the most common dataset (frequent itemset) in a large dataset [12][13][14]. The FP-Growth algorithm process only mapping data or scans the database twice to build a "tree" structure so that it is also known as the FP-Tree algorithm [5]. Using the FP-Tree structure, the FPGrowth algorithm can directly extract frequent itemset from the FP-Tree arrangement that has been formed [15]. The FPGrowth algorithm is divided into three main steps: generation of Conditional Pattern Base, FP-tree conditional generation and frequent itemset search [2].

\section{ME THODOLOGY}

The research methodology goes through the steps shown in Figure 1 below.

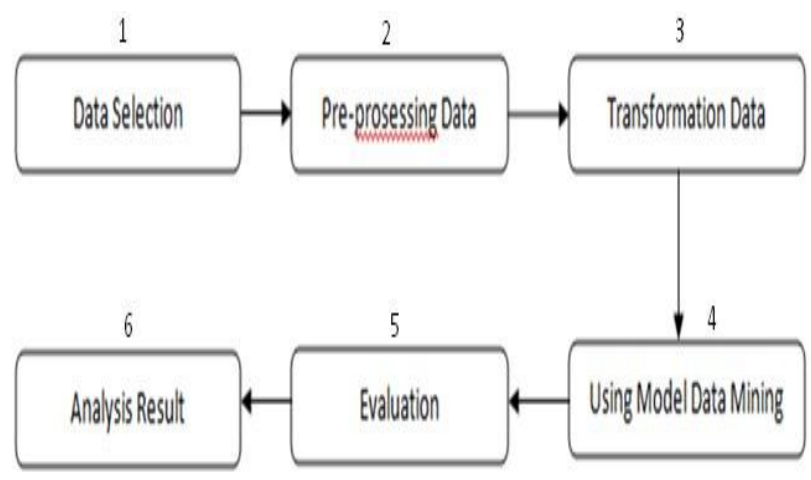

Fig 1: Proposed

\subsection{Data Collection}

In this process the selection of dataset in a database is then selected the target dataset, entities or attributes that will be processed for research. The results of the data selection are then paired in a file or an entity that is different from the operational database [16][17]. This study the data used transaction data from 2016 to 2018 with 2,534,033 rows of data.

Table 1. Data Selection Sample

\begin{tabular}{|c|c|c|c|}
\hline Attibut & Description & Data Type & Data \\
\hline 1 & Transaction_number & Char & 003133-30042015-0026 \\
\hline 2 & Seq & Char & 1 \\
\hline 3 & PLU & Char & 8232653289675 \\
\hline 4 & Item_Description & Varchar & CHOCO/BRA, 9,L \\
\hline 5 & Qty & Decimal & 1 \\
\hline 6 & Price & Money & 249000 \\
\hline 7 & Customer_ID & Char & 476448 \\
\hline 8 & Spending_Program_Id & Char & 2 \\
\hline 9 & Transaction_Time & Char & 1 \\
\hline 10 & CardNo & Char & 8091200016076900 \\
\hline 11 & Card_Name & Varchar & HERI SUSANTO \\
\hline
\end{tabular}




\begin{tabular}{|c|c|c|c|}
\hline 12 & Class & Char & UCL \\
\hline 13 & DP2 & Char & LD \\
\hline 14 & Description & Char & CHOCO/BRA, 9,L \\
\hline 15 & Brand & Varchar & UNDERCOLORS \\
\hline
\end{tabular}

\subsection{Preprocessing Data}

This process is carried out by the integration of several entities that constitute data that will be carried out research. Integration makes data simpler and can be adjusted to the required attributes. This step is also carried out checking inconsistent data, data noise, duplicate data and correcting data errors without changing the data contents [6]. After integrating data into 1005232 rows.

Table 2. Example of Dataset

\begin{tabular}{|c|c|c|c|c|c|}
\hline No & Cust_Id & Date & Qty & Amount & Class \\
\hline 1 & CUST_1 & 17012016 & 1 & 480000 & BON \\
\hline 2 & CUST_1 & 17012016 & 1 & 188000 & QBY \\
\hline 3 & CUST_1 & 30012016 & 1 & 465000 & PYO \\
\hline$\cdots$ & $\cdots$ & $\cdots$ & $\cdots$ & $\cdots$ & $\cdots$ \\
\hline 1005230 & CUST_221468 & 30102017 & 1 & 799000 & ANV \\
\hline 1005231 & CUST_221469 & 22042017 & 2 & 885000 & CLQ \\
\hline 1005232 & CUST_221469 & 22042017 & 2 & 1200000 & UDC \\
\hline
\end{tabular}

Table 2, contains the customer id, date of purchase, number of items purchased, total purchases and class or brand of items purchased. Based on Table 2, it can be seen that customers buy several classes or brands of items and at different time.

\subsection{Transformation Data}

This process changes or transforms data from the initial data into data following the format of the data mining process [18] without changing the contents of the data [15][19]. In this stage the process of summarizing (aggregation), pivoting and changing numeric types to the binominal.



Fig 2: Transformation Data

In Figure 2, it can see the data transformation process with several sub processes are aggregate, pivot, rename and replacing and replace missing value. A more detailed process description can be seen below.

* Operator No.1: The process of retrieving data to be processed, the data can be in the form of extension excel files, CSV (Comma-Separated Values) files and can be SQL Server database. The next data will be processed by the next operator. This operator can be used to access the repository.

* Operator No.2: Aggregate is a process used to produce value by classifying the same value by determining certain criteria. Many aggregation functions including
SUM, COUNT, MIN, MAX, AVERAGE, and many other similar functions.

* Operator No.3: The Pivot operator rotates the Dataset from row to column and vice versa by grouping several attribute values from the same group into one value and summarizing the data in various calculations (sum, average, and others)

* Operator No.4: This operator can be used to replace the name of a set of attributes by replacing part of the attribute name with the specified replacement.

* Operator No.5: This operator replaces the Missing value in the selected attribute example with the specified 
replacement. Missing values can be replaced by Zero, minimum, maximum or average values of that attribute.
* Operator No.6: This operator is used to write or save CSV (Comma-Separated Values) files.

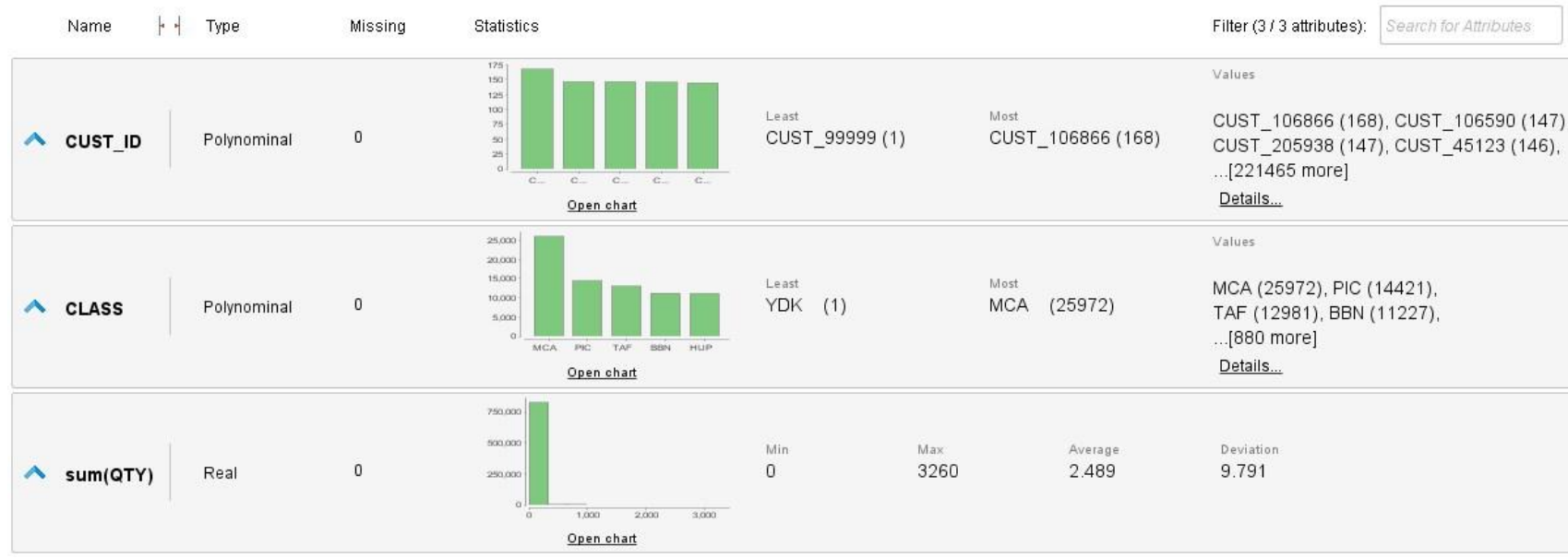

Fig 3: Result Aggregate

In Figure 3, it can see the results of the aggregate process, these results show the class or brand that is most sold and customers who often shop. The data can be used to manage inventory items and to find out loyal customers so they can personally promote the product.

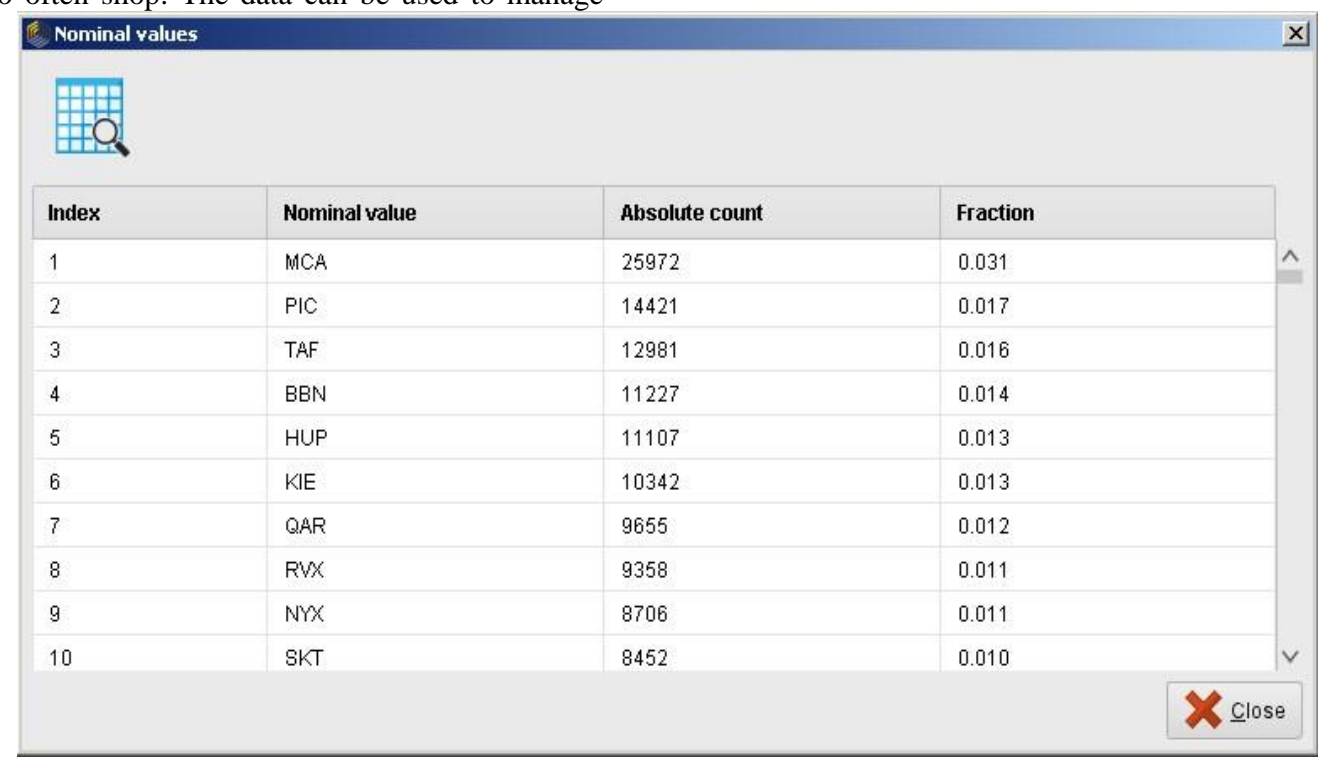

Fig 4: Best-Selling Item

Base on Figure 4, shows the best-selling items as inventory management recommendations so that the company will provide good inventory to meet customer needs and will not store unsold goods. For example, sales in the 2016- 2018 MCA sold 25,972 items and were the most sold items.

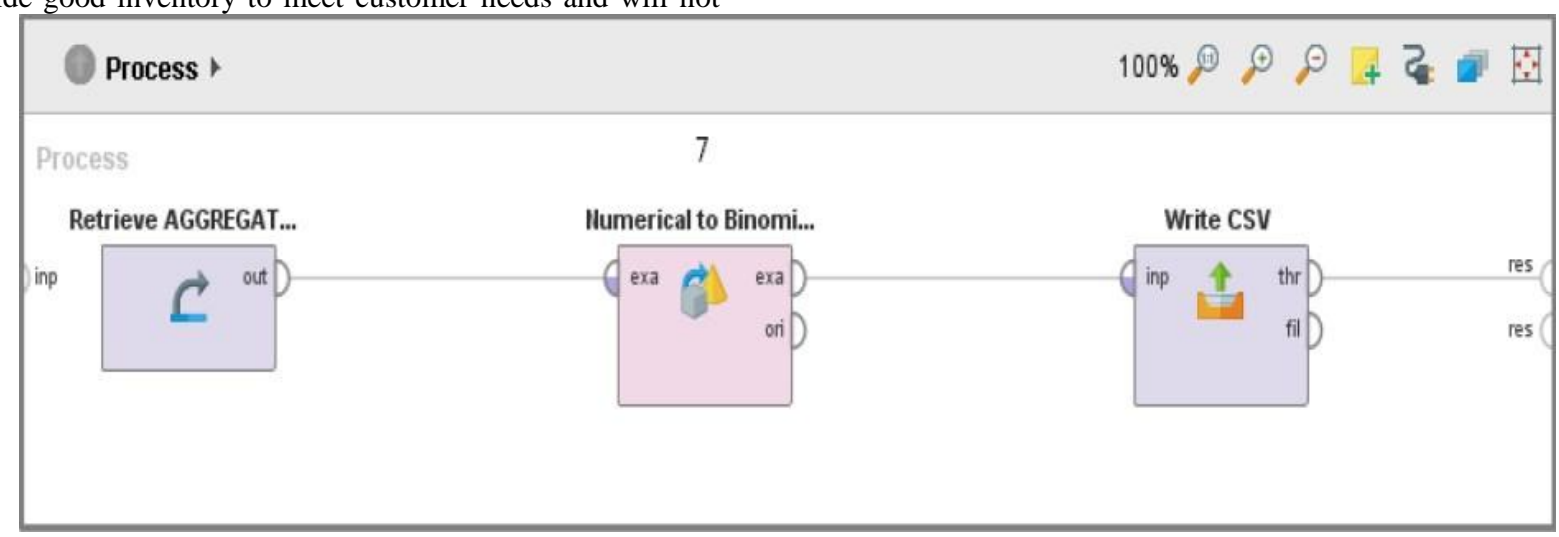

Fig 5: Numerical to Binominal 
Figure 5, shows the numerical to binominal process with the aim that the data can be processed using the FP-Growth algorithm. Detail Process as described below.

* Operator No.7: The Numeric Operator to Binominal changes the numeric attribute type to a binominal type (also called binary). This operator not only changes the selected attribute type but also maps all the values of this attribute to the corresponding binominal values. The binominal attribute can only have two possible values which are 'true' or 'false'. If the attribute value is between the minimum and maximum values specified, it becomes 'false', otherwise 'true'. The minimum and maximum values can be determined by the min and max parameters respectively. If the value is lost, the new value will be lost. The default limits are both set to 0.0 so that only 0.0 is mapped to 'false' and all other values are mapped to 'true' by default.

\subsection{Model Data Mining}

Data that has been through the process of data selection, preprocessing and transformation, then the data will be processed using RapidMiner. The steps for processing association rules are shown below.

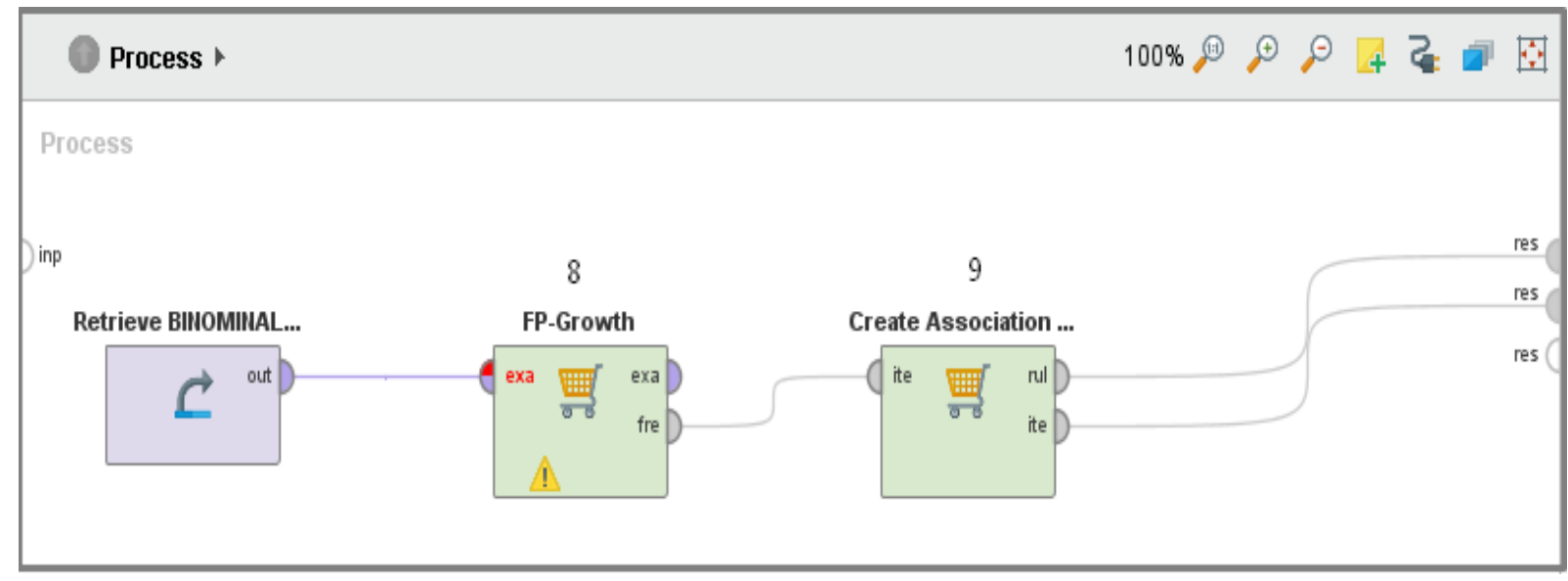

Fig 6: Data Mining Model

In figure 6 , shows the data mining process model using the FP-Growth algorithm. The process can run if the data has gone through the preprocessing process in Figure 2 and transformation in Figure 5. More detailed information on the information below.

* Operator No.8: This operator efficiently calculates all sets of items that often arise from a given dataset using the FP-tree data structure. This operator can run if all the values in the attribute are of type binominal.

* Operator No.9: This operator generates a set of association rules from the set of items that appear frequently. Association rules statements that help uncover relationships between seemingly unrelated data. An example of an association rule is "If a customer buys eggs, he is $80 \%$ likely to also buy milk." The association rules has two parts, the antecedent (if) and the consequent (then). An antecedent is an item (or itemset) found in the data. A consequence is an item (or itemset) that is found in combination with an antecedent.

\subsection{Evaluation}

Evaluation is done by testing data with different minimum support and minimum confidence values to find the best values and rules. Here are the results of testing the data.

\subsubsection{Analysis of the Effect of Minimum Support on Frequent Itemset}

Table 3. Frequent Itemset

\begin{tabular}{|c|c|c|c|c|c|}
\hline \multirow{2}{*}{ Item Set } & \multicolumn{5}{|c|}{ Minimum Support } \\
\cline { 2 - 6 } & $\mathbf{1 0 \%}$ & $\mathbf{2 0 \%}$ & $\mathbf{3 0 \%}$ & $\mathbf{4 0 \%}$ & $\mathbf{5 0 \%}$ \\
\hline 1 & 19 & 9 & 4 & 4 & 4 \\
\hline 2 & 50 & 20 & 6 & 6 & 6 \\
\hline
\end{tabular}

\begin{tabular}{|c|c|c|c|c|c|}
3 & 46 & 16 & 4 & 4 & 2 \\
\hline 4 & 14 & 5 & 1 & 1 & 0 \\
\hline TOTAL & $\mathbf{1 2 9}$ & $\mathbf{5 0}$ & $\mathbf{1 5}$ & $\mathbf{1 5}$ & $\mathbf{1 2}$ \\
\hline
\end{tabular}

The following item sets are formed from the minimum support from $10 \%$ to $50 \%$. In Table 2, shows data for a minimum support of $10 \%$ produces 129 frequent itemsets with itemset of 4 . Minimum support of $20 \%$ produces 50 frequent itemsets with itemset of 4. A minimum support of $30 \%$ produces 15 frequent itemsets with itemset of 4 . Minimum support $40 \%$ produces 15 frequent itemsets with itemset of 4 . Minimum support 50\% produces 12 frequent itemsets with itemset of 3. In Table 3, it can be concluded that the greater the minimum support, the fewer the number of items produced [2][7] and the stronger the association relationship between attributes in the rules formed [20].

Table 4. Minimum Support $10 \%$

\begin{tabular}{|c|c|c|c|c|c|}
\hline Size & Support & Item 1 & Item 2 & Item 3 & Item 4 \\
\hline 1 & 0.994 & PYO & & & \\
\hline 1 & 0.991 & BON & & & \\
\hline 1 & 0.989 & QBY & & & \\
\hline$\cdots$ & $\cdots$ & $\cdots$ & $\cdots$ & $\cdots$ & $\cdots$ \\
\hline 4 & 0.032 & PYO & BON & QBY & YSL \\
\hline 4 & 0.032 & PYO & BON & QBY & SOR \\
\hline 4 & 0.032 & PYO & BON & QBY & SUU \\
\hline
\end{tabular}


Based on Table 4, with a minimum support of $10 \%$, it can see the itemsets formed and the items, for ex sample the itemset of four consists of classes or brands PYO, BON, Q BY and YSL.

Table 5. Minimum Support 20\%

\begin{tabular}{|c|c|c|c|c|c|}
\hline Size & Support & Item 1 & Item 2 & Item 3 & Item 4 \\
\hline 1 & 0.994 & PYO & & & \\
\hline 1 & 0.991 & BON & & & \\
\hline 1 & 0.989 & QBY & & & \\
\hline$\cdots$ & $\cdots$ & $\cdots$ & $\cdots$ & $\cdots$ & $\cdots$ \\
\hline 4 & 0.055 & PYO & BON & QBY & TAF \\
\hline 4 & 0.048 & PYO & BON & QBY & BBN \\
\hline 4 & 0.047 & PYO & BON & QBY & HUP \\
\hline
\end{tabular}

Based on Table 5, with a minimum support of $20 \%$, it can see the itemsets formed and the items. For ex sample the itemset of four consists of classes or brands PYO, BON, QBY and TAF.

Table 6. Minimum Support 30\%

\begin{tabular}{|c|c|c|c|c|c|}
\hline Size & Support & Item 1 & Item 2 & Item 3 & Item 4 \\
\hline 1 & 0.994 & PYO & & & \\
\hline 1 & 0.991 & BON & & & \\
\hline 1 & 0.989 & QBY & & & \\
\hline$\cdots$ & $\cdots$ & $\cdots$ & $\cdots$ & $\cdots$ & $\cdots$ \\
\hline 3 & 0.114 & PYO & QBY & MCA & \\
\hline 3 & 0.114 & BON & QBY & MCA & \\
\hline 4 & 0.113 & PYO & BON & QBY & MCA \\
\hline
\end{tabular}

Based on Table 6, with a minimum support of $30 \%$, it can see the itemsets formed and the items. For ex sample the itemset of four consists of classes or brands PYO, BON, QBY and MCA.

Table 7. Minimum Support $\mathbf{4 0 \%}$

\begin{tabular}{|c|c|c|c|c|c|}
\hline Size & Support & Item 1 & Item 2 & Item 3 & Item 4 \\
\hline 1 & 0.994 & PYO & & & \\
\hline 1 & 0.991 & BON & & & \\
\hline 1 & 0.989 & QBY & & & \\
\hline$\cdots$ & $\cdots$ & $\cdots$ & $\cdots$ & $\cdots$ & $\cdots$ \\
\hline 3 & 0.114 & PYO & QBY & MCA & \\
\hline
\end{tabular}

\begin{tabular}{|c|c|c|c|c|c|}
3 & 0.114 & BON & QBY & MCA & \\
\hline 4 & 0.113 & PYO & BON & QBY & MCA \\
\hline
\end{tabular}

Based on Table 7 , with a minimum support of $40 \%$, it can see the itemsets formed and the items. For ex sample the itemset of four consists of classes or brands PYO, BON, QBY and MCA.

Table 8. Minimum Support 50\%

\begin{tabular}{|c|c|c|c|c|}
\hline Size & Support & Item 1 & Item 2 & Item 3 \\
\hline 1 & 0.994 & PYO & & \\
\hline 1 & 0.991 & BON & & \\
\hline 1 & 0.989 & QBY & & \\
\hline$\cdots$ & $\cdots$ & $\cdots$ & $\cdots$ & $\cdots$ \\
\hline 2 & 0.115 & QBY & MCA & \\
\hline 3 & 0.973 & PYO & BON & QBY \\
\hline 3 & 0.114 & PYO & BON & MCA \\
\hline
\end{tabular}

Based on Table 8 , with a minimum support of $40 \%$, it can see the itemsets formed and the items. For example the itemset of three consists of classes or brands PYO, BON and MCA.

\subsubsection{Analysis of the Effects of Minimum Support and Minimum Confidence}

At this stage, the rules are generated following the value of confidence that has been determined in this study. Confidence referred to in this study is the value of the tendency of an item with certain items to be purchased by the customer simultaneously. From a confidence value of $60 \%$ to $90 \%$, it is expected to produce the best rule. The following is the rule result for each confidence value, which are:

Table 9. Number of Rule

\begin{tabular}{|c|c|c|c|c|c|}
\hline \multirow{2}{*}{ MinConf } & \multicolumn{5}{|c|}{ MinSup } \\
\cline { 2 - 6 } & $\mathbf{1 0 \%}$ & $\mathbf{2 0 \%}$ & $\mathbf{3 0 \%}$ & $\mathbf{4 0 \%}$ & $\mathbf{5 0 \%}$ \\
\hline $60 \%$ & 292 & 109 & 31 & 31 & 18 \\
\hline $70 \%$ & 292 & 109 & 31 & 31 & 18 \\
\hline $80 \%$ & 292 & 109 & 31 & 31 & 18 \\
\hline $90 \%$ & 292 & 109 & 31 & 31 & 18 \\
\hline
\end{tabular}

Based on Table 9, it can be seen that with minimum support $50 \%$ and minimum confidence of $90 \%$ produces 18 the number of rule. With the combination of minimum support and minimum confidence, the lift ratio can be seen in Table 10.

Table 10. Lift Ratio

\begin{tabular}{|c|c|c|c|c|c|}
\hline No & Premises & Conclusion & Support & Confidence & Lift \\
\hline 1 & MCA & PYO, BON & $11.45 \%$ & $97.63 \%$ & 0.99185212 \\
\hline 2 & PYO & BON, QBY & $97.32 \%$ & $97.95 \%$ & 1.00013798 \\
\hline 3 & MCA & QBY & $11.52 \%$ & $98.23 \%$ & 0.99365002 \\
\hline 4 & BON & PYO, QBY & $97.32 \%$ & $98.25 \%$ & 1.00008007 \\
\hline
\end{tabular}




\begin{tabular}{|c|c|c|c|c|c|}
5 & QBY & PYO, BON & $97.32 \%$ & $98.44 \%$ & 1.00012702 \\
\hline 6 & MCA & PYO & $11.57 \%$ & $98.65 \%$ & 0.99283225 \\
\hline 7 & BON, MCA & PYO & $11.45 \%$ & $98.68 \%$ & 0.993117 \\
\hline 8 & BON & QBY & $97.93 \%$ & $98.86 \%$ & 1.00003798 \\
\hline 9 & PYO & QBY & $98.24 \%$ & $98.87 \%$ & 1.0000959 \\
\hline 10 & PYO, BON & QBY & $97.32 \%$ & $98.87 \%$ & 1.00012702 \\
\hline 11 & MCA & BON & $11.60 \%$ & $98.94 \%$ & 0.99877523 \\
\hline 12 & PYO, MCA & BON & $11.45 \%$ & $98.97 \%$ & 0.99906169 \\
\hline 13 & QBY & BON & $97.93 \%$ & $99.06 \%$ & 1.00003798 \\
\hline 14 & PYO & BON & $98.43 \%$ & $99.06 \%$ & 1.00004895 \\
\hline 15 & PYO, QBY & BON & $97.32 \%$ & $99.07 \%$ & 1.00008007 \\
\hline 16 & BON & PYO & $98.43 \%$ & $99.37 \%$ & 1.00004895 \\
\hline 17 & QBY & PYO & $98.24 \%$ & $99.37 \%$ & 1.0000959 \\
\hline 18 & BON, QBY & PYO & $97.32 \%$ & $99.37 \%$ & 1.00013798 \\
\hline
\end{tabular}

The lift ratio test stage produces a size for test the validity of the rules that have been formed. Lift ratio to know the strength of the association rules. Lift ratio is a comparison between confidence for a rule divided by benchmark confidence, which is assumed to be consequent and antecedent mutually independent. Consequent is a consequence or item that will be purchased after buying an antecedent. Antecendent is the reason that makes the item consequent. If the $\mathrm{K} \rightarrow \mathrm{L}$ rules are obtained, then $\mathrm{K}$ is antecedent and $\mathrm{L}$ is consequent. To get the lift ratio value using equation:

Lift Ratio $=\frac{\text { Confidence }(K, L)}{\text { Benchmark Confidence }(K, L)}$

To get the benchmark confidence value it self can be calculated using the following equation:

Benchmark Confidence $=\frac{N C}{N} \quad[20]$

Information:

$\mathrm{Nc}=$ number of transactions with items that become consequent.

$\mathrm{N}=$ number of database transactions.

Lift ratio values greater than one indicate the benefits of these rules. The higher the lift ratio value, the greater the association strength. Lift ratio measures how important the rule is formed based on the value of support and confidence. Lift Ratio is a value that shows the validity of the transaction process and provides information on whether product $\mathrm{K}$ was purchased together with product $\mathrm{L}$.

Based on Table10, it can be seen that the lift ratio for association rules has a greater value 1 . This shows that all the rules are strong and valid to be used as a reference to find out the relationship or correlation between items [2][7]. The higher the lift ratio, the greater the strength of the association [21].

\section{RESULT AND DISCUSSION}

Based on the results of the study it can be seen that with a minimum support of $10 \%$ produces as many as four itemset with a total of 129 items and with a minimum support of 50\% produces as many as three itemset with a total of 12 items.
Combination of minimum support is $10 \%$ and minimum support is $60 \%$, minimum support is $10 \%$ and minimum support of $70 \%$, minimum support of $10 \%$ and minimum support of $80 \%$, minimum support of $10 \%$ and minimum support of $90 \%$ resulting in the same number of association rules totaling 292 . Then with a minimum support of $50 \%$ and minimum confidance of $90 \%$ resulting in association rules that at least 18 and the average lift ratio is more than 1.

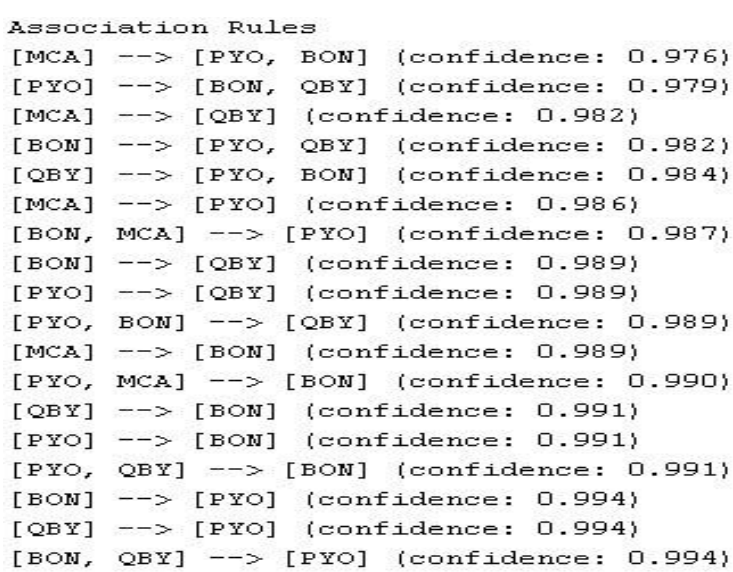

\section{Fig 7: Association Rules}

In Figure 7, it can be seen that the rules result in minimum confidence are $97.63 \%$ and maximum confidence is $99.37 \%$. The association rules can be seen that BON, QBY has a correlates with PYO, with a confidence value of more than $97 \%$. Combination of minimum support and minimum confidence can be a recommendation for the right product promotion.

\section{CONCLUSION}

The results of the study concluded that:

1. The higher of the minimum support value used in the study will result in a smaller number of item sets. Accurate results for determining product promotion recommendations can be measured using a lift ratio. A transaction is said to be valid if it has a lift ratio value of more than 1 , which means that in the transaction, $\mathrm{K}$ and $\mathrm{L}$ products are purchased simultaneously. The lift ratio 
measures the importance of rules that have been formed based on the value of support and confidence. For experiments, the minimum support value is $10 \%-50 \%$ and the minimum confidence value is $60 \%-90 \%$. Choosing the best combination of minimum support and minimum confidence to produce good association rules has a lift ratio value of more than 1 .

2. Based on the analysis of the results of testing the data mining function using the FP-Growth algorithm produces the highest support value of $98.43 \%$, the highest confidence value of $99.37 \%$ and the highest lift ratio of 1,00013798. The higher the value of the parameters used in processing with the FP-Growth algorithm, the fewer rules produced, the stronger the association relationship between the attributes in the rules formed.

3. The results of the study provide information on the products that are the most sold and the least sold. Product promotion recommendations can be done by selling bestselling products of top ten are MCA, PIC, TAF, BBN, HUP, KIE, QAR, RVX, NYX and SKT with less-salable products by bundling sales.

4. The results of the research provide information about what products are the most sold can be a product inventory system strategy. So that it can provide items to meet customer demand as well as proper item placement for best-selling of top ten are MCA, PIC, TAF, BBN, HUP, KIE, QAR, RVX, NYX and SKT with unsold items.

\section{REFERENCES}

[1] A. Abdullah, "Rekomendasi Paket Produk Guna Meningkatkan Penjualan Dengan Metode FP-Growth," Khazanah Inform. J. Ilmu Komput. dan Inform., vol. 4, no. 1, p. 21, 2018.

[2] D. Sukma and D. Fitrianah, "Data Mining Analysis with Association Rules Method to Determine the Result of Fish Catch using FP-Growth Algorithm," Int. J. Comput. Appl., vol. 181, no. 15, pp. 7-15, 2018.

[3] N. Arincy and I. S. Sitanggang, "Association rules mining on forest fires data using FP-Growth and ECLAT algorithm," Proc. - 2015 3rd Int. Conf. Adapt. Intell. Agroindustry, ICAIA 2015, pp. 274-277, 2016.

[4] F. Fitriyani, "Implementasi Algoritma Fp-Growth Menggunakan Association Rule Pada Market Basket Analysis," J. Inform., vol. 2, no. 1, 2016.

[5] A. Wahana, D. S. Maylawati, M. Irfan, and H. Effendy, "Supply chain management using fp-growth algorithm for medicine distribution," J. Phys. Conf. Ser., vol. 978, no. $1,2018$.

[6] A. N. S. Putro and R. I. Gunawan, "Implementasi Algoritma FP-Growth Untuk Strategi Pemasaran Ritel Hidroponik (Studi Kasus : PT. HAB),” J. Buana Inform., vol. 10, no. 1, p. 11, 2019

[7] M. I. Ghozali, R. Z. Ehwan, and W. H. Sugiharto, "Analisa Pola Belanja Menggunakan Algoritma Fp Growth, Self Organizing Map (Som) Dan K Medoids," Simetris J. Tek. Mesin, Elektro dan Ilmu Komput., vol. 8, no. 1, pp. 317-326, 2017.

[8] M. Kaur and S. Kang, "Market Basket Analysis: Identify the Changing Trends of Market Data Using Association
Rule Mining," Procedia Comput. Sci., vol. 85, no. Cms, pp. 78-85, 2016.

[9] N. Hashimoto, S. Ozawa, T. Ban, J. Nakazato, and J. Shimamura, "A Darknet Traffic Analysis for IoT Malwares Using Association Rule Learning," Procedia Comput. Sci., vol. 144, pp. 118-123, 2018.

[10] W. Feng, Q. Zhu, J. Zhuang, and S. Yu, "An expert recommendation algorithm based on Pearson correlation coefficient and FP-growth," Cluster Comput., pp. 1-12, 2018.

[11] K. Sumangkut, A. S. M. Lumenta, and V. Tulenan, "Analisa Pola Belanja Swalayan Daily Mart Untuk Menentukan Tata Letak Barang Menggunakan Algoritma FP-Growth,” J. Tek. Inform., vol. 8, no. 1, 2016.

[12] Midhunchakkaravarthy, Divya, D. Bhattacharyya, and T. H. Kim, "Evaluation of product usability using improved FP-Growth frequent itemset algorithm and DSLC - FOA algorithm for alleviating feature fatigue," Int. J. Adv. Sci. Technol., vol. 117, pp. 163-180, 2018.

[13] W. T. Lin and C. P. Chu, "A fast and parallel algorithm for frequent pattern mining from big data in many-task environments," Int. J. High Perform. Comput. Netw., vol. 10, no. 3, pp. 157-167, 2017.

[14] M. Yin, W. Wang, Y. Liu, and D. Jiang, "An improvement of FP-Growth association rule mining algorithm based on adjacency table," MATEC Web Conf., vol. 189, pp. 0-6, 2018.

[15] R. Anggrainingsih, N. R. Khoirudin, and H. Setiadi, "Discovering drugs combination pattern using fp-growth algorithm," Int. Conf. Electr. Eng. Comput. Sci. Informatics, vol. 4, no. September, pp. 735-738, 2017.

[16] A. -, F. Marisa, and D. Purnomo, "Penerapan Algoritma Apriori Terhadap Data Penjualan di Toko Gudang BM," Penerapan Algoritm. Apriori Terhadap Data Penjualan di Toko Gudang BM, vol. 1, no. 1, pp. 1-5, 2016.

[17] Y. Gao, Q. Zhang, L. Chen, K. Wang, N. Chen, and H. Liu, "Research on application of FP-tree based association rule mining on test sequence in train control system," Res. Appl. FP_tree based Assoc. rule Min. test Seq. train Control Syst., pp. 9993-9997, 2017.

[18] H. Herasmus, “Analisa Customer Service System Menggunakan Metode Data Mining Dengan Algoritma Fp-Growth (Studi Kasus Di Pt Batamindo Investment Cakrawala)," J. Tek. Ibnu Sina JT-IBSI, vol. 2, no. 2, pp. 31-43, 2017.

[19] K. Dharmarajan and M. A. Dorairangaswamy, "Analysis of FP-growth and Apriori algorithms on pattern discovery from weblog data," 2016 IEEE Int. Conf. Adv. Comput. Appl. ICACA 2016, pp. 170-174, 2016.

[20] A. R. Riszky and M. Sadikin, "Data Mining Menggunakan Algoritma Apriori untuk Rekomendasi Produk bagi Pelanggan," J. Teknol. dan Sist. Komput., vol. 7, no. 3, p. 103, 2019.

[21] Y. Jumiati and N. Bahtiar, "Pengembangan Sistem Informasi Data KB dan Analisis Pola Pemilihan Metode Kontrasepsi Menggunakan Algoritma Sql-Based FpGrowth," PERFORMA Media Ilm. Tek. Ind., vol. 15, no. 1, pp. 70-76, 2016. 